\title{
$\mathrm{VII} \mathrm{CINCCI}$
}

VII Colóquio internacional sobre Comércio e Cidade

Fortaleza, 03 a 07 de Novembro de 2020

\section{Espaços culturais para valorização da identidade local}

Cultural spaces to enhance local identity

Espacios culturales para mejorar la identidad local

RAMOS, Marcos Roberto; Mestre; Universidade Federal de Santa Catarina (UFSC) marcosdesignramos@gmail.com

SILVA, Diego Borges da; Mestre; Universidade Federal de Santa Catarina (UFSC) bordiego@gmail.com

TRISKA, Ricardo; Dr. Eng.; Universidade Federal de Santa Catarina (UFSC) ricardo.triska@gmail.com

\section{Resumo}

Este artigo analisa modelo de negócios de patrimônio histórico cultural e propõe soluções por meio do Design, a fim de evidenciar, valorizar, enfatizar a experiência do usuário e a identidade local. Assim, realizou-se um estudo aplicado, com abordagem qualitativa e objetivo exploratório, contribuindo para uma discussão teórica acerca da Gestão de Design, aplicados em dois estudos de caso. Como resultado, percebe-se que nem sempre a estratégia aplicada ao negócio considera os aspectos culturais em sua comunicação com o público-alvo, o que fragiliza a percepção de identidade e conexão do usuário com o espaço cultural, com implicações, nem sempre positivas nas proposições de seu uso.

Palavras-chave: Gestão de Design. Modelo de negócios. Identidade. Design Território. Design de Experiência.

\section{Cultural spaces to enhance local identity}

\section{Abstract}

This article analyzes the business model of historical cultural heritage and proposes solutions through Design, in order to highlight, value, emphasize the user experience and the local identity. Thus, an applied study was carried out, with a qualitative approach and exploratory objective, contributing to a theoretical discussion about Design Management, applied in two case studies. As a result, it is clear that the strategy applied to the business does not always consider cultural aspects in its communication with the target audience, which weakens the user's perception of identity and connection with the cultural space, with implications, not always positive in propositions of its use. 


\section{$\mathrm{VII} \mathrm{CINCCl}$}

VII Colóquio internacional

sobre Comércio e Cidade

Fortaleza, 03 a 07 de Novembro de 2020

Keywords: Design Management. Business model. Identity. Territory Design. Experience Design.

\section{Espacios culturales para mejorar la identidad local}

\section{Resumen}

Este artículo analiza el modelo de negocio del patrimonio cultural histórico y propone soluciones a través del diseño para resaltar, valorar, enfatizar la experiencia del usuario y la identidad local. Así, se realizó un estudio aplicado, con un enfoque cualitativo y un objetivo exploratorio, que contribuyó a una discusión teórica sobre la Gestión del Diseño, aplicada en dos estudios de caso. Como resultado, se advierte que la estrategia aplicada al negocio no siempre considera los aspectos culturales en su comunicación con el público objetivo, lo que debilita la percepción del usuario de la identidad y la conexión con el espacio cultural, con implicaciones, no siempre positivas en proposiciones de su uso.

Palabras clave: Administración de diseño. Modelo de negocio. Identidad. Diseño del territorio. Experiencia de diseño. 


\section{Introdução}

O design, enquanto área de atuação multidisciplinar, contribui em diferentes perspectivas no desenvolvimento estratégico das empresas. Explorando o conceito de valor, atua como transformador na percepção e concepção do negócio em empresas de diversos segmentos.

Considerando esta visão, aqui, aborda-se a Gestão de Design voltada à estratégia de negócios para promoção de produtos e serviços, tendo como objeto de estudo dois patrimônios históricos culturais do estado de Santa Catarina, respectivamente o Mercado Público da cidade de Itajaí, localizada no litoral norte do estado e a Casa da Alfândega, localizada na capital do estado, Florianópolis. Estes são importantes referências para promoção e divulgação da cultura local, sendo rota de turistas e moradores que buscam produtos da identidade local, marcada pela colonização açoriana.

Neste sentido, as estratégias e resultados esperados com a aplicação deste estudo visam tanto aspectos mercadológicos, bem como proporcionar resgate, preservação e promoção da cultura regional, traduzindo-a como um fator de diferenciação dos produtos e serviços comercializados.

Esse contexto envolve análise e intervenção nessas duas organizações, que têm origem pela colonização açoriana e identidade associada, principalmente, a atividade pesqueira. Outro aspecto a ser considerado é o cenário atual do estado, com crescimento na área econômica e no turismo, onde essa população de perfil diferenciado, anseia por serviços com qualidade superior, atendendo suas expectativas, em todos os aspectos.

O litoral de Santa Catarina vive um momento de expansão da sua visibilidade, em virtude da melhoria da infraestrutura, com instalação de empresas de diferentes áreas. Neste contexto, também se destaca a implantação de grandes empreendimentos, ampliando o fluxo de turistas e moradores na região, além de sua localização estratégica no litoral catarinense (Figura 1), na Costa Verde e Mar, contribuindo para o turismo da região.

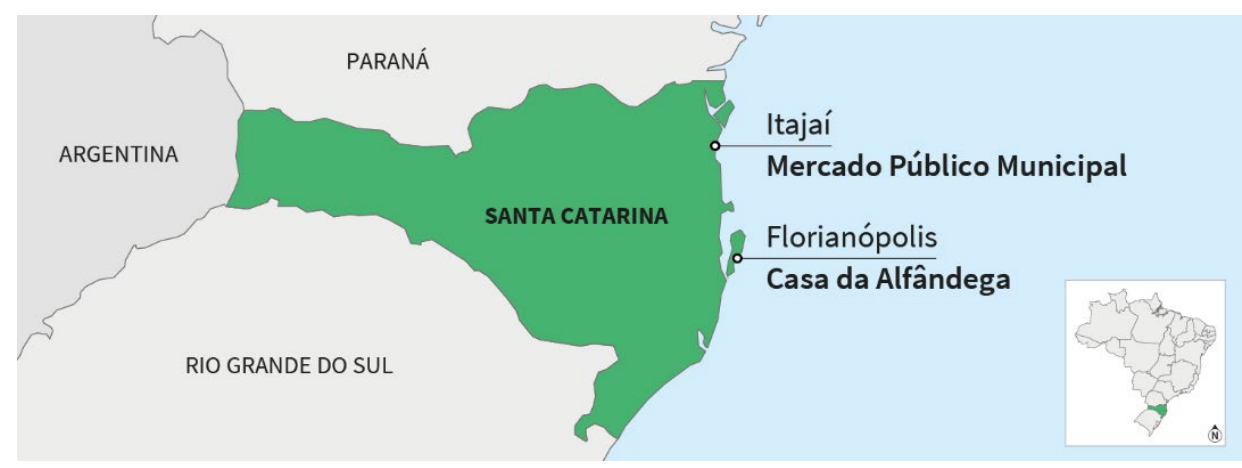

Figura 1: Localização dos patrimônios histórico-culturais pesquisados

Fonte: Dos autores, 2020.

Assim, se vê a importância e a oportunidade em se aplicar o design como fator estratégico, principalmente para a melhoria na qualidade dos produtos e serviços disponibilizados, conforme apresentado anteriormente, e também como uma solução para preservação, resgate e promoção de aspectos da identidade local, para que a partir destes espaços os usuários percebam uma representação 
das características naturais da localidade e, assim, consigam visualizar a relação entre esses espaços, o local (região) em que está inserido e os serviços disponibilizados, promovendo a imagem desses espaços.

A partir do exposto, surgiu como hipótese de pesquisa: como o design, baseado na Gestão de Design, pode contribuir para a estruturação de modelos de negócios em patrimônios históricos culturais que resgatem, preservem e promovam a cultura local.

Desta forma, pretende-se trabalhar com um recorte de interesse conceitual, para formulação de um plano de intervenção almejando a promoção de produtos e serviços com a caracterização da identidade e promoção da imagem dessas organizações. Assim, o estudo foi estruturado a partir dos procedimentos metodológicos, da fundamentação teórica e apresentação, análise e discussão dos resultados.

\section{Procedimentos Metodológicos}

Para analisar a questão da identidade e cultura local e seus potenciais para patrimônios históricos sob o viés do design, desenvolve-se um estudo de natureza básica, com abordagem qualitativa, objetivando fazer um estudo exploratório para aproximar conceitos (GIL, 2010). Assim, relacionou-se conceitos de Gestão de Design e questões de cultura e identidade local, relacionando patrimônio histórico e cultural, como base para fundamentar as relações entre as temáticas.

\subsection{Modelo CDS - Competitividade, Diferenciação e Sustentabilidade}

Para realizar o diagnóstico do Mercado Municipal de Itajaí, utilizou-se como ferramenta o modelo CDS, desenvolvido na Universidade Federal de Santa Catarina (UFSC), no Núcleo de Gestão de Design (NGD), que tem por objetivo a análise organizacional a partir de três dimensões: Competitividade, Diferenciação e Sustentabilidade. (MERINO; GONTIJO; MERINO, 2011).

Partindo dessas dimensões, o modelo atua com a definição de indicadores para cada uma delas, servem como base e são escolhidos por meio da relevância para a avaliação (NGD, 2016). Neste sentido, a própria cartilha orientadora de aplicação do CDS sugere alguns indicadores.

Esses indicadores são selecionados de acordo com sua relevância para o projeto em questão. Neste aspecto, tem-se que considerar apenas o fato de se ter o mesmo número de indicadores em cada dimensão, para posterior formulação das médias por indicadores. Seguindo na utilização desse modelo, então, definem-se critérios para a mensuração dos indicadores estabelecidos.

Em seguida, é realizada a mensuração, onde os critérios ganham nota e uma cor na escala Likert (Figura 2), de acordo com a condição de aferição apresentada em cada critério. A partir das notas, então, é organizada a média de cada indicador, qual apresenta a situação de cada dimensão e alterando, posteriormente, a cor desses, ocasionando também a alteração da cor da dimensão, tendo em vista a média obtida entre os indicadores. 


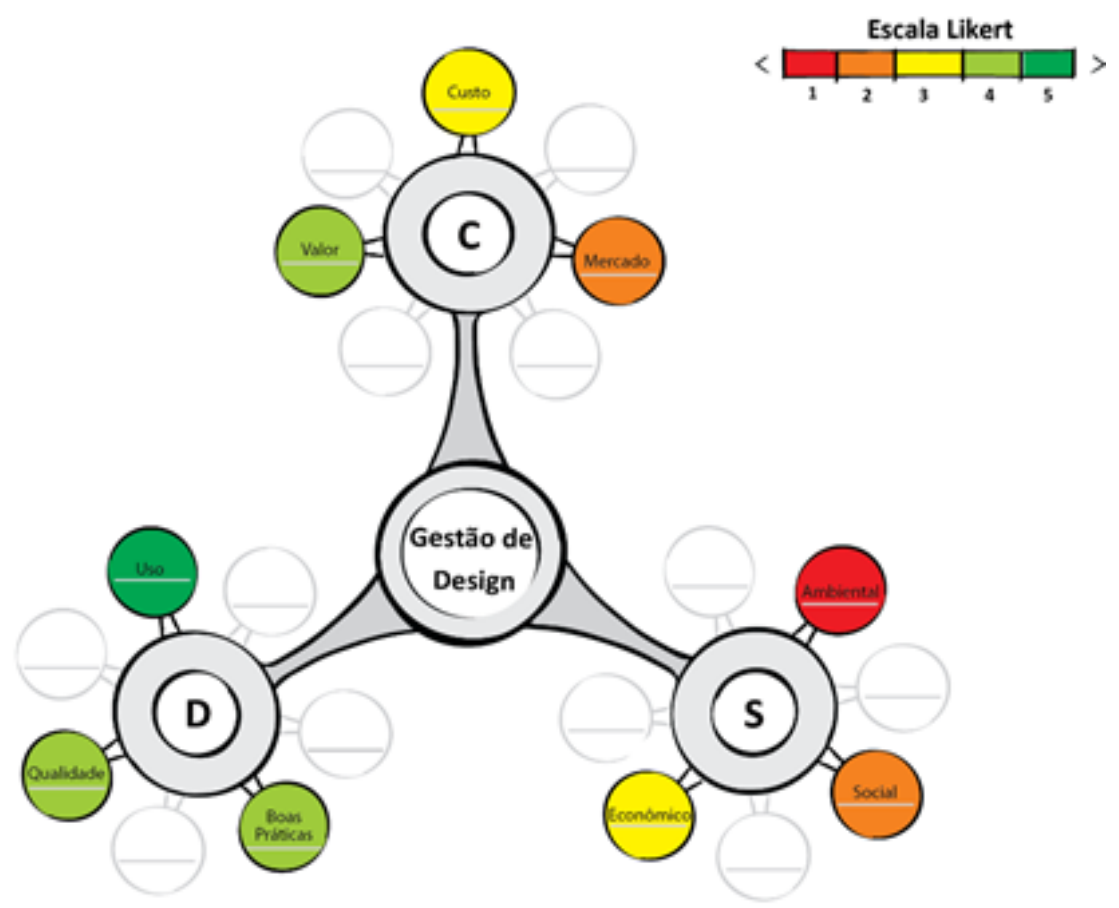

Figura 2: Modelo CDS

Fonte: NGD/UFSC, 2016.

Atuando com esse caráter, principalmente visual, a opção por esta ferramenta se dá em função da sua objetividade e também por proporcionar uma visão global do objeto estudado. Para proporcionar um diagnóstico do Mercado Municipal de Itajaí, essa utiliza de representação visual, identificando as potencialidades e fragilidades da empresa e, posteriormente, planejando determinada intervenção.

Assim, com a aplicação do modelo CDS, pretende-se "identificar o nível de cada indicador e, consequentemente, propor as ações que se desdobrarão em metas, permitindo transformar as fragilidades detectadas em potencialidades e/ou reduzir os impactos negativos de cada um deles." (NGD, 2016).

\subsection{Modelo Business Model Canvas}

Para realizar o diagnóstico da Casa da Alfândega, utilizou-se o modelo Business Model Canvas (BMC), de Osterwalder (2004), uma ferramenta de gerenciamento estratégico, que permite desenvolver e esboçar modelos de negócio novos ou existentes, pré-formatado em um mapa visual de nove blocos (Figura 3) do modelo de negócios. 


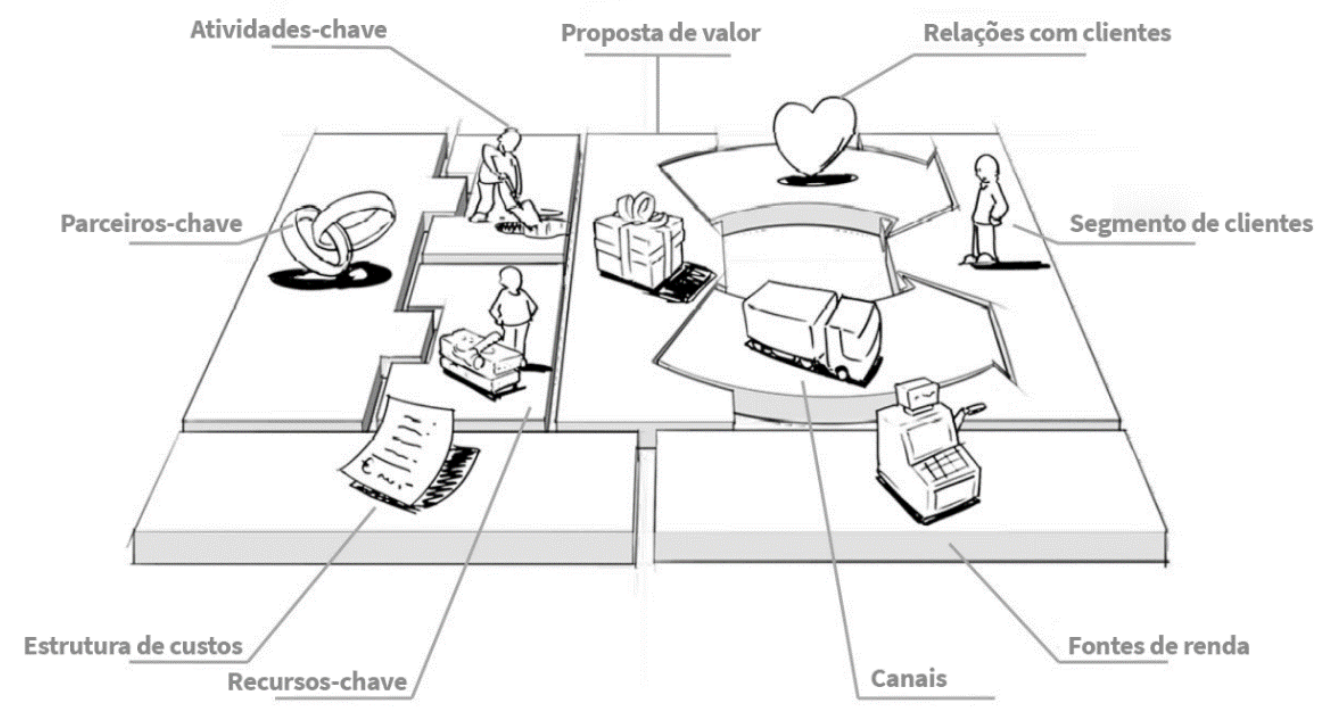

Figura 3: Modelo Business Model Canvas

Fonte: Osterwalder, 2004.

O debate sobre modelo de negócios inicia-se por suas definições e sobre seus componentes principais, refletindo diferentes pontos de vista sobre as aplicações das diversas atividades compreendidas por modelo de negócios. Para proporcionar um diagnóstico da Casa da Alfandega, essa utiliza de representação visual, identificando as potencialidades e fragilidades da empresa e, posteriormente, planejando determinada intervenção.

De acordo com Stickdorn e Schneider (2014, p. 214), "o Canvas vem ganhando cada vez mais popularidade e pode ser usado praticamente em qualquer setor, beneficiando os provedores de serviços de inúmeras maneiras". Segundo Aquino (2015, p. 12), aplica-se o BMC para estabelecer "um conceito simples, relevante, intuitivo e compreensível a qualquer organização que queira descrever e manipular seu modelo de negócio", no sentido de gerar novas estratégias, desafiar suas preconcepções e inovar de maneira eficiente e eficaz. Assim, a estrutura do BMC cobre as quatro principais áreas de um negócio: clientes; oferta; infraestrutura e viabilidade financeira.

\section{A Gestão de Design}

A aplicação da Gestão de Design dentro das organizações vem evoluindo junto com o amadurecimento das organizações, bem como das mudanças nos modelos de gestão administrativas. Diante desse processo de globalização, a função do design foi se moldando ao longo das transformações ocorridas no contexto socioeconômico pela introdução de novas tecnologias e teorias.

No entendimento de Den Otter e Emmitt (2008), design é um processo social que estimula a comunicação da equipe na compreensão individual do projeto que precisa ser produzido coletivamente. Quer dizer, design não é apenas a resolução de problemas, mas também uma forma de os encontrar. Talvez, por isso, recentemente tem havido um interesse crescente em relação à Gestão de Design. 
Para Mozota (2011), a Gestão de Design acompanha as evoluções da gestão e, apesar de determinadas diferenças referentes às abordagens cognitivas, suas áreas possuem muitos pontos convergentes. Assim, design é um processo, e não apenas uma forma, que por isso deve estar relacionado com a beleza de objetos, num segundo nível, mas que, num primeiro momento, tem a ver com toda a abordagem do modo de fazer negócios, servir clientes e oferecer valor.

Agregar valor à organização deve ser o foco da Gestão de Design. Esse processo é realizado por meio de uma abordagem da integração de equipes multidisciplinares de maneira a conceber, constituir, implementar e gerar projetos, envolvendo a integração de conhecimentos especializados.

Compreender o significado de se agregar valor à empresa é um processo complexo, visto que a tomada de decisões para esse efeito pode ser inerentemente imprevisível (KESTLE; LONDON, 2002). De acordo com Kestle (2009), a integração de equipes multidisciplinares contribui para o conceito, a construção e a gerência, sendo fundamental para desenvolver e concretizar a geração de valor em projetos para o cliente e as partes interessadas. A deficiente integração de conhecimentos especializados das partes interessadas, usuário e produtor, pode ter consequências de longo alcance, como a síntese inadequada da análise de necessidades, levando à baixa geração de valor para o cliente e os usuários finais.

A Gestão de Design tem sido entendida a partir de vários pontos de vista. Ballard e Koskela (1998) a consideram em três pontos: processo de transformação de insumos em produtos; fluxo de informação por meio do tempo e do espaço; processo para gerar valor para os clientes. Entendendo que esses pontos não são alternativos, e sim complementares, sendo que a Gestão de Design é integrada à transformação, ao fluxo e ao valor.

Assim, promover a valorização da cultura de Santa Catarina, representada neste estudo pelo Mercado Público de Itajaí e pela Casa da Alfândega, atividades do terceiro setor, existe uma carência de valor agregado e de características distintivas, que pode ter o seu ciclo de compra isolado, único, não contribuindo para uma geração contínua de renda, que acaba por fragilizar ainda mais as relações produtivas dos grupos.

Por isso, identifica-se a importância da Gestão de Design na construção de uma tecnologia social, em que o design se torne a ponta do processo, o resultado tangível. Com um sistema produtivo mais eficiente, em que se respeite as características produtivas de um grupo cultural, pode-se aliar o saber-fazer local às necessidades estéticas do mercado formal. Visto que de nada adianta um processo produtivo solidário sem um produto que possa ser competitivo estética e funcionalmente, da mesma forma que não adianta um produto competitivo sem uma identidade de marca, que o diferencie, o valide e o sustente.

\section{Design, Identidade e Cultura Local}

A atividade de Design é reconhecida com uma prática multidisciplinar que contribui cada vez mais para o desenvolvimento de produtos com excelência. Design tem a ver com qualidade. "O valor do Design é que ele reconcilia arte com indústria. $\mathrm{O}$ 'bom design' pode ser ornamental ou funcional, de acordo com a época, uma vez que os designers são herdeiros tanto dos artesãos quanto da Bauhaus". (MOZOTA, 2011, p. 51). 
Considerando que uma das características que marca determinado local é a cultura que é representada nas características do povo, como tradição e hábitos, quanto mais evidente esta for, mais marcantes serão estas lembranças na memória do usuário. Em síntese, a cultura "é um conjunto de representações, símbolos, valores e crenças compartilhados pelo grupo de pessoas que constitui a instituição". (MOZOTA, 2011, p. 188). Assim, essa "instituição" pode ser considerada uma determinada região, uma organização ou outro tipo de agrupamento.

Pensando-se em evidenciar esses símbolos, valores e crenças, presentes na cultura, é que se faz importante conhecer de maneira aprofundada a região e, assim, poder valorizar, evidenciando métodos e técnicas utilizados na fabricação e apresentação de produtos ou serviços, que em grande parte dos casos é desenvolvido de maneira particular em cada região.

De acordo com Barrera (2010), o Design é o elo central entre economia e cultura, pois ao mesmo tempo em que concebe produtos com o desenvolvimento de signos e símbolos para exploração comercial, esses acabam sendo consumidos pelo valor que representam na sociedade. E essa geração de valor que é intrínseca ao design. Então, principalmente essa valorização, pretende utilizar de fundamento a cultura da região. De acordo com Du Gay et al. (1997, p. 3), a cultura é um processo que envolve diversas relações, conforme demonstrado na Figura 4:

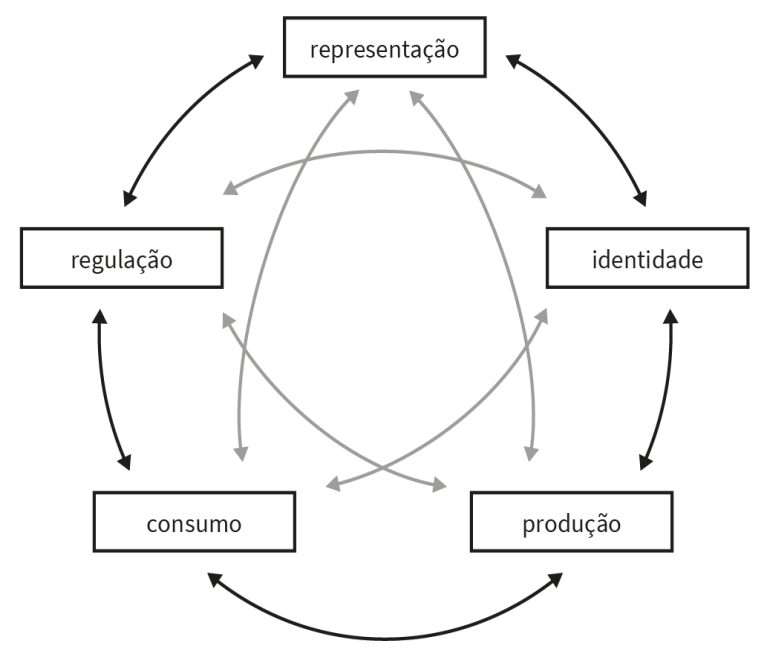

Figura 4: O circuito da cultura

Fonte: Adaptado de Du Gay et al. (1997, p. 3).

Na Figura 04 é possível perceber que o circuito da cultura é organizado de forma que todas as etapas podem ser retornadas a todo o momento. Primordialmente, passa por etapas de representação, identidade, produção, consumo e regulação, em que havendo coerência entre esses cinco eixos, há contribuição para preservação e fortalecimento da cultura de determinada região.

Na visão de Canclini (2008), a cultura é vista como um fenômeno que contribui para reproduzir ou transformar um sistema social a partir de seus símbolos e representações. Assim, torna-se um processo que produz significados influenciando no estilo de vida, de ideias e de valores. 
Desta forma, é possível compreender a complexidade com que é definida a cultura, pois a sociedade está em constante evolução. Neste contexto, se faz importante evidenciar os fatores principais para que mesmo com as constantes modificações na sociedade, a cultura e a identidade do local sejam preservadas. "A identidade nasce da cultura e vice-versa" (VILLAS-BOAS, 2002, p.55). Estes dois fatores são fundamentais e indissociáveis em um processo de resgate, preservação e proteção da cultura principalmente. Segundo Ono (2004), as culturas, que são conjuntos de significados e interconexões que desde o nascimento fazem parte do indivíduo. Lê-se aqui que esse indivíduo não necessariamente é uma pessoa, mas pode também se apresentar como um grupo de pessoas que vivem em um mesmo local e dividem experiências e conhecimentos onde passam a produzir símbolos e representações que os unificam, tornando-os uma associação, um bairro, um estado, uma nação, constituindo assim uma identidade local.

Produtos comercializados em espaços como o Mercado Público e a Casa da Alfândega, possuem forte conexão com o local que os gerou. Pensando nessa forte conexão do produto com o seu local de origem, o design atua de maneira estratégica, comunicando as qualidades com eficiência, por meio de marcas, embalagens e outras interfaces.

Conforme detalhado na caracterização de Design, os aspectos envolvidos visam o fortalecimento e geração de uma identidade sólida e coerente com os objetivos da organização, que sirva de fator para diferenciação frente ao Mercado e a Casa da Alfândega. Identidade é um termo geralmente associado a questões de personalidade dos indivíduos. Para compreender melhor o termo, parte-se do exposto por Martins e Merino (2011):

Identidade compreende as formas adotadas por uma empresa para identificar-se ou posicionar seu produto. Cria uma "imagem" intencional e uma reputação favorável na mente de seus stakeholders. (MARTINS; MERINO, 2011, p. 132).

Essa identidade então, é que dá vida a organização, tornando-a reconhecível. Ela traduz de maneira objetiva a mensagem que a organização busca transmitir por meio de seus produtos e serviços. "A identidade se obtém por meio de uma real e coerente integração entre produto, produção, comunicação e comercialização". (MORAES, 2010, p. 45).

Nesta visão, o desenvolvimento de diversos elementos que possuam características comuns entre si, e que estejam diretamente associados ao objetivo, e foco da empresa, são aspectos relevantes para a criação de uma identidade. Possuindo esses elementos, a organização, pode-se dizer, que se apresenta para o mercado pois a "identidade é o DNA da empresa: o conjunto de atributos que a faz única, diferente de todas as outras". (FASCIONI, 2010, p. 22).

Se tratando neste estudo, de dois patrimônios históricos de Santa Catarina, principalmente a identidade deve criar, evidenciar e valorizar características da cultura e produção local.

\section{Apresentação do diagnóstico}

Após o levantamento bibliográfico, seguiu-se à aplicação prática dos conceitos abordados. Neste sentido, foi desenvolvido um estudo de caso para o Mercado Público de Itajaí e outro para a Casa da Alfândega, a partir de duas metodologias, 
a fim de verificar potencialidades e fragilidades dessas organizações, sendo realizado um diagnóstico da situação atual.

Assim, trabalhou-se no posicionamento das marcas e nas imagens das organizações, transparecendo a identidade local e a cultural de Santa Catarina. Com base no diagnóstico foi possível discutir a atuação da Gestão de Design para a promoção de produto e serviço.

Assim, primeiro são apresentados os resultados do diagnóstico e, em seguida, a construção de um plano de intervenção, idealizado durante a aplicação dos métodos, sendo o modelo CDS para o Mercado Público e o Canvas para a Case da Alfândega.

\subsection{Diagnóstico do Mercado Público de Itajaí}

Para utilização do modelo CDS, com base nas análises iniciais, foram organizados os indicadores para cada dimensão, ficando estabelecidos na dimensão Competitividade os indicadores: Mercado (que condiz com o ambiente externo), Infraestrutura (associando tanto a parte física quanto de pessoal) e Inovação (quanto à produtos); na dimensão Diferenciação utilizou-se o indicador Identidade (que aborda aspectos da imagem/identificação dos produtos e serviços e também sua coerência com a identidade local), Produtos/serviços (que envolvem características próprias dos produtos e serviços disponibilizados) e Qualidade, que abrange a qualidade na entrega dos produtos e serviços quanto à sua forma e função, entre outros aspectos. Por fim, na dimensão Sustentabilidade, trabalhouse com os indicadores Cultural (preocupação com a manutenção da cultural local no espaço), Econômico (financeiro) e Social (inserção do espaço no contexto da cidade). Em síntese, o modelo CDS ficou organizado da seguinte forma (Figura 5):

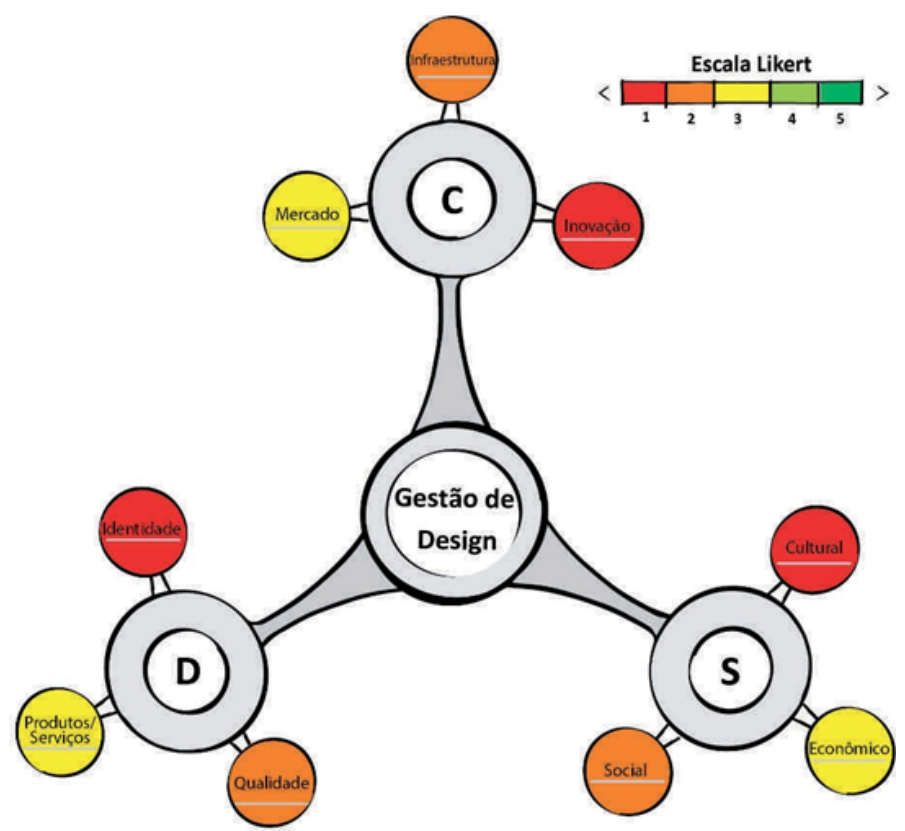

Figura 5: Resultados do Diagnóstico, a partir do Modelo CDS

Fonte: Dos autores, com base em NGD/UFSC, 2016.

Neste cenário foi possível perceber que diversos aspectos envolvendo competitividade, diferenciação e sustentabilidade, na oferta de produtos e serviços, 
possuíam deficiências. Em uma análise ampla, percebeu-se que em cada uma das dimensões havia um indicador com resultado grave.

Na dimensão de Competitividade o fator de Inovação foi diagnosticado como o mais preocupante, em função da não observação de produtos com aspectos diferenciados e que trouxessem potenciais de inovação. Muitos produtos eram encontrados em diversos outros locais e já eram comercializados há algum tempo, necessitando sua "atualização" (não descaracterização).

$\mathrm{Na}$ dimensão de Diferenciação o fator mais evidente foi a questão da Identidade, percebendo-se a descaracterização da identidade local, uma vez que alguns serviços disponibilizados não se preocupavam com a oferta de produtos locais. Além disso, o espaço não possuía identidade visual, nem a apresentação dos produtos era padronizada.

$\mathrm{Na}$ dimensão Sustentabilidade a preocupação com a cultura local não foi evidenciada nos momentos da observação. O espaço apresentava-se com foco mais voltado ao viés comercial, onde os produtos que possuíam melhor potencial de vendas, estavam ali dispostos, independentemente de sua origem.

Assim, após o diagnóstico obtido, surgiu a ideia em desenvolver um plano de intervenção que atendesse às deficiências encontradas e compreendesse a Gestão de Design, atuando nos três níveis (estratégico, tático e operacional). Neste sentido foram estruturadas e organizadas as ações que deram origem ao Plano de Intervenção do Mercado Público de Itajaí.

\subsection{Diagnóstico da Casa da Alfândega}

O debate sobre modelo de negócios inicia-se por suas definições, refletindo diferentes pontos de vista sobre as aplicações das diversas atividades compreendidas por modelo de negócios. Assim, o Business Model Canvas (OSTERWALDER, 2004), descrito por meio de nove blocos básicos, mostra a lógica de como uma organização pretende gerar valor.

Desta forma, nesta etapa foi realizado um workshop com a administração da Casa da Alfandega, com o objetivo de demonstrar o uso da ferramenta e os benefícios que poderiam ser alcançados na organização com a utilização desta. $O$ workshop foi realizado na sede da Casa da Alfândega, durou aproximadamente duas horas e contou com a participação três colaboradores da organização: a supervisora; a assistente administrativa que também é artesã; e a responsável pelo controle de estoque, além de uma artesã convidada para esta atividade, que faz parte do projeto Casa da Alfandega desde 1988.

Ao final do workshop, chegou-se a tela de modelo de negócios da Casa da Alfandega (Figura 6), pautado na ferramenta Canvas, dividido em quatro blocos principais: PARA QUEM?, O QUÊ?, QUANTO?; COMO?. 


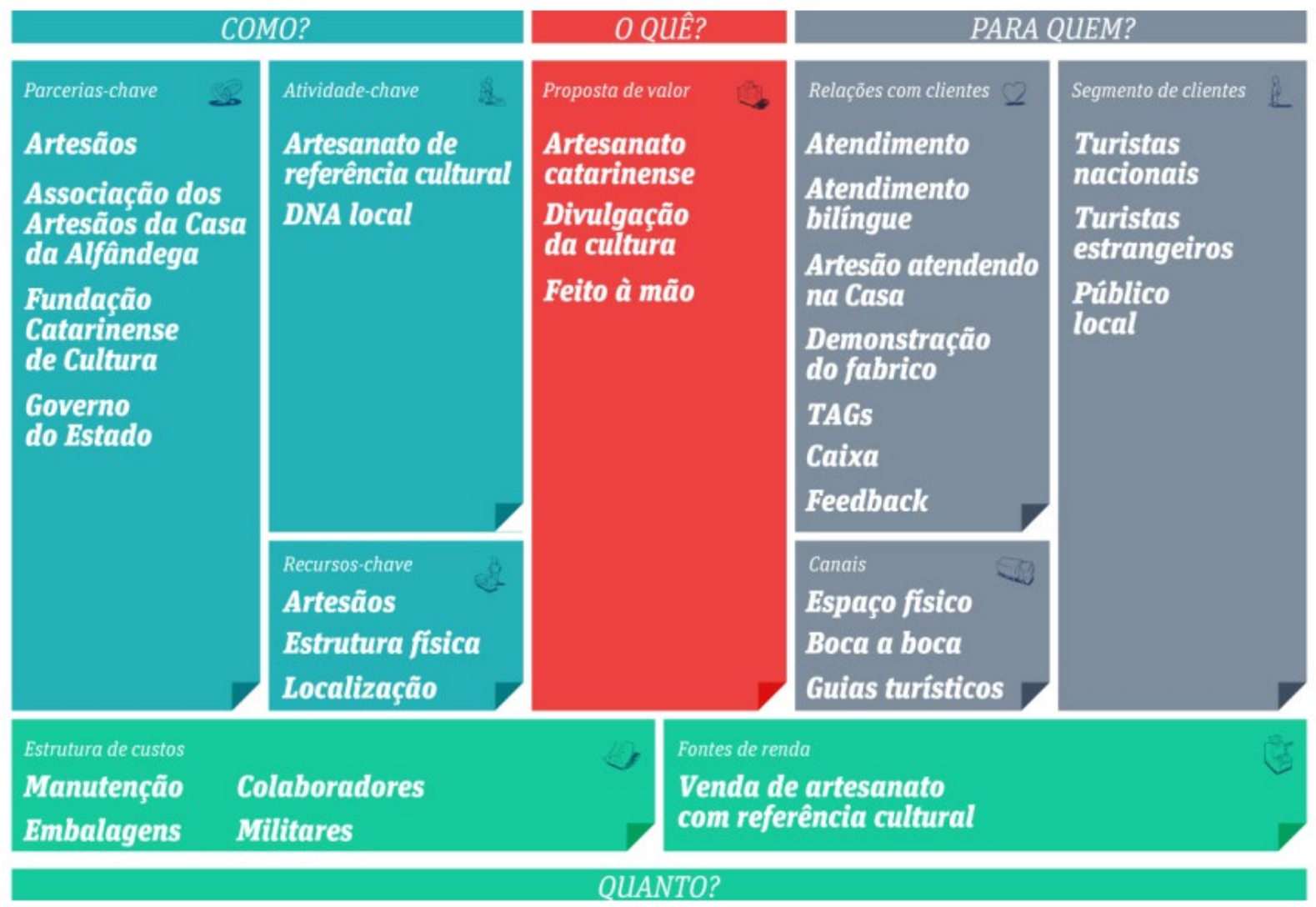

Figura 6: Resultado do workshop

Fonte: Dos autores, 2020.

Por meio da aplicação dessa ferramenta, ficou evidente que os colaboradores e a artesã que participaram deste workshop conseguiram visualizar a organização e perceber novos caminhos para alcançar uma melhor gestão na Casa. Além do mais, com essa aplicação foi possível verificar problemas que foram percebidos durante os 18 meses em que o diagnóstico foi realizado, em conjunto com a supervisora da organização, que sequer eram percebidos no dia a dia dos colaboradores e artesãos.

Com base nesse diagnóstico foi possível idealizar o Plano de Intervenção, que atendesse às deficiências encontradas e compreender a Gestão de Design. Neste sentido, foram estruturadas e organizadas as ações de implementação a curto, médio e longo prazo, que deram origem ao Plano de Intervenção da Casa da Alfandega.

\section{Plano de Intervenção}

Aliando o conhecimento teórico obtido a partir do referencial teórico, o conhecimento prático a partir dos estudos de caso e as experiências profissionais dos pesquisadores, foi estabelecida uma abordagem para melhorar a interface de serviço desenvolvida no Mercado Público Municipal de Itajaí e na Casa da Alfândega.

Nesse sentido, se propôs um Plano de Intervenção como instrumento de gestão orientado para a tomada de decisões internas e, necessariamente, para a 
realização de ações. O plano tem objetivo, não só sistematizar esses processos, entretando servir como uma ferramenta que dê garantias para mudanças em curso, bem como implementar a capacidade de resposta às ameaças e as oportunidades identificadas durante a fase de diagnóstico.

\subsection{Plano de Intervenção: Mercado Público de Itajaí}

Após as análises, até então detalhadas, quanto à questão envolvendo identidade e infraestrutura do espaço, se fez fundamental para implementação das ações propostas neste estudo, o elenco de ações de intervenção. Estas foram organizadas em um quadro, objetivando a melhoria dos resultados apresentados pelo espaço, com base no diagnóstico apresentado. Assim, a Tabela 1 foi organizada com os seguintes resultados:

Tabela 1: Totais de ações de intervenção geradas

\begin{tabular}{|l|c|c|c|}
\hline \multicolumn{1}{|c|}{ Dimensões } & Indicadores & $\begin{array}{c}\text { Problemas } \\
\text { diagnosticados }\end{array}$ & Ações propostas \\
\hline Competitividade & 3 & 6 & 6 \\
\hline Diferenciação & 3 & 8 & 9 \\
\hline Sustentabilidade & 3 & 8 & 8 \\
\hline Totais & $\mathbf{9}$ & $\mathbf{2 2}$ & $\mathbf{2 3}$ \\
\hline
\end{tabular}

Fonte: Dos Autores, 2020.

Conforme demonstra a distribuição de ações organizadas por dimensões na Tabela 1, estas foram estruturadas em quadros específicos e, também, especificado seu nível de intervenção no viés da Gestão de Design, denominando se a ação seria uma responsabilidade do nível operacional (colaboradores), estratégico (gerentes ou condôminos) ou tático (Administração do Condomínio e Fundação Cultural).

Após a apresentação das ações sugeridas no Plano de Intervenção e, passada todas as etapas de diagnóstico das fragilidades do espaço, percebeu-se que algumas das questões que causavam maior impacto na Identidade Corporativa, prejudicavam a infraestrutura e até a oferta de produtos e serviços, de alguma forma, encontram-se parcialmente contempladas nos documentos formais do Mercado Público, porém, para que estas práticas se efetivem, é fundamental o acompanhamento constante por parte da Fundação Cultural de Itajaí, que administra o espaço. Percebeu-se no desenvolvimento deste estudo, um certo distanciamento entre os objetivos propostos pela Fundação Cultural e as ações executadas no espaço do Mercado Público.

Outra questão preocupante, é a Identidade ou falta de padronização dos elementos visuais presentes no espaço, o que prejudica, em muito, a oferta de produtos e serviços, uma vez que toda a parte de comunicação é realizada de maneira individual, ou seja, cada uma das salas possui seu modo de divulgação (sites, redes sociais, materiais impressos, entro outro) como também sua própria assinatura, não criando a ideia de unidade que consolidaria e fortaleceria a identidade do espaço. 


\subsection{Plano de Intervenção: Casa da Alfândega}

Foi estabelecida uma abordagem para melhorar a interface de serviço desenvolvida na Casa da Alfândega. Neste sentido, se propôs um Plano de Intervenção como instrumento de gestão orientado para a tomada de decisões internas e necessariamente para a realização de ações. O plano teve como objetivo, não só sistematizar o processo, mas ser, sobretudo, uma ferramenta que desse garantias de sucesso às mudanças em curso, bem como implementar a capacidade de resposta às ameaças e às oportunidades.

O Plano de Intervenção buscou prevenir ou minimizar uma situação problema identificada neste diagnóstico, objetivando atingir determinadas metas, beneficiando direta ou indiretamente colaboradores, artesãos e usuários.

Esse foi entregue à administração da Casa da Alfândega (Tabela 2), a partir das hipóteses levantadas durante este estudo. Sua estrutura foi fundamentada em três níveis de implantação: curto, médio e longo prazo, norteando a execução das estratégias de aplicação. 
Tabela 2: Plano de intervenção para a Casa da Alfândega

\begin{tabular}{|c|c|c|}
\hline Aspectos-chave & Recomendações & Priorização \\
\hline Acessibilidade & $\begin{array}{l}\text { Adequar as instalações, conforme norma de acessibilidade a } \\
\text { edificações (ABNT NRB 9050) e do Iphan }\end{array}$ & Longo prazo \\
\hline $\begin{array}{l}\text { Agenda } \\
\text { da semana }\end{array}$ & $\begin{array}{l}\text { Ampliar o número de artesãos que participam da } \\
\text { demonstração do fabrico }\end{array}$ & Médio prazo \\
\hline $\begin{array}{l}\text { Artesãos de } \\
\text { outras regiões }\end{array}$ & $\begin{array}{l}\text { Ampliar a participação de artesãos de outras regiões do } \\
\text { estado para representar as diversas culturas de Santa } \\
\text { Catarina }\end{array}$ & Médio prazo \\
\hline Capacitação & $\begin{array}{l}\text { Realizar cursos e treinamentos com os colaboradores, no } \\
\text { sentido de qualificar o atendimento }\end{array}$ & Médio prazo \\
\hline Estatuto interno & Definir missão, visão e valores & Médio prazo \\
\hline Identidade visual & Elaboração da identidade visual & Curto prazo \\
\hline $\begin{array}{l}\text { Integração } \\
\text { entre os artesãos }\end{array}$ & $\begin{array}{l}\text { Capacitar e propor a integração entre os artesãos, no sentido } \\
\text { de ampliar e agregar valor aos produtos e ao serviço }\end{array}$ & Médio prazo \\
\hline $\begin{array}{l}\text { Organização do } \\
\text { espaço interno }\end{array}$ & $\begin{array}{l}\text { Contratar um profissional de arte para organizar e melhorar a } \\
\text { distribuição dos produtos e peças em exposição }\end{array}$ & Médio prazo \\
\hline $\begin{array}{l}\text { Pesquisa } \\
\text { de público }\end{array}$ & $\begin{array}{l}\text { Realizar pesquisa de público, a fim de propor estratégias para } \\
\text { a captação de novos clientes }\end{array}$ & Médio prazo \\
\hline $\begin{array}{l}\text { Posicionamento } \\
\text { de marca }\end{array}$ & $\begin{array}{l}\text { Desenvolver métodos para criar ou fortalecer a imagem da } \\
\text { marca, incorporando além das qualidades técnicas, as } \\
\text { qualidades que enfatizem a relação da marca com os clientes }\end{array}$ & Médio prazo \\
\hline $\begin{array}{l}\text { Prédio } \\
\text { da Alfândega }\end{array}$ & $\begin{array}{l}\text { Resgatar e divulgar a importância histórica do prédio da } \\
\text { Alfândega }\end{array}$ & Médio prazo \\
\hline $\begin{array}{l}\text { Site e } \\
\text { mídias sociais }\end{array}$ & $\begin{array}{l}\text { Desenvolver um redesenho no site, tornando-o mais moderno, } \\
\text { dinâmico e organizado. Bem como divulgar as ações em } \\
\text { redes sociais, como Facebook e Instagram }\end{array}$ & Curto prazo \\
\hline Sinalização & Projeto de sinalização interna e externa & Médio prazo \\
\hline TAGs & $\begin{array}{l}\text { Criar um padrão visual para as etiquetas que acompanham as } \\
\text { peças comercializadas na Casa. Bem como aplicação de } \\
\text { informações bilíngue aos produtos comercializados }\end{array}$ & Médio prazo \\
\hline $\begin{array}{l}\text { Tenda do } \\
\text { artesanato }\end{array}$ & $\begin{array}{l}\text { Divulgar o projeto Casa da Alfândega nos bairros e praias de } \\
\text { Florianópolis, com a participação de artesãos }\end{array}$ & Médio prazo \\
\hline Uniformes & $\begin{array}{l}\text { Implantar o uso de uniformes entre os colaboradores. Além } \\
\text { do reforço da imagem da marca, transmitindo organização, } \\
\text { credibilidade, segurança e profissionalismo }\end{array}$ & Curto prazo \\
\hline
\end{tabular}

Fonte: Dos autores, 2020.

Como resultado final deste estudo, conclui se que a disciplina de Design está se tornando cada vez mais popular em diversos segmentos do mercado, da engenharia a outras áreas da tecnologia e da gestão, se aproximando cada vez do conceito social e humano do design.

Assim, para um serviço que demanda visão holística, sugere-se investir na contratação de um profissional de design. Nosso papel, enquanto profissionais que querem fazer a diferença, seja na academia ou no mercado, é quebrar esse 
paradigma de que só grandes organizações podem contar com designers em suas equipes.

Por fim, o distanciamento das práticas culturais destes espaços é reconhecido e concebido para trocas de saberes e fazeres da região. Contudo, o resgate dessas práticas, principalmente com forte caráter local, além da disponibilização de espaços culturais geraria maior aproximação da população com as organizações Mercado Público e a Casa da Alfândega -, fortalecendo o caráter de pertencimento, fazendo com que artesãos locais sentissem contemplados e valorizados em manter a os valores regionais a partir da cultura.

\section{Conclusão}

A associação entre Design e Identidade é fator primordial para as organizações. Estas, necessitam saber como comunicar sua identidade para criar uma imagem no seu público, que transpareça sua missão, visão e ação. O design, enquanto atividade estratégica, proporciona o estreitamento dessa relação e, principalmente, em casos como o deste estudo (patrimônio histórico), sua potencialidade. Ainda, evidenciando a cultura, interpretando-a e traduzindo-a como fator diferencial e competitivo.

A partir da ampliação da visão do design, não apenas como uma atividade operacional, mas sim, com um caráter totalmente estratégico, proporcionado pela Gestão de Design, foi possível desenvolver e efetivar ao longo deste estudo de design e valor são indissociáveis, e quando bem aplicados, proporcionam vantagens competitivas para a organização. Assim, foi caracterizada e evidenciada as potencialidades do design, a partir de uma visão estratégica, para o desenvolvimento de produtos e serviços, principalmente com caráter de preservação, resgate e potencialização da cultura local.

A partir das diversas observações realizadas aos dois espaços culturais, objeto deste estudo, pode-se perceber a relevância do design no contexto social e sua contribuição para a promoção da identidade e potencialização de produtos e serviços.

Acredita-se que o resultado obtido tenha proporcionado uma visão sistemática sobre o Mercado Público e a Casa da Alfândega, a partir de um olhar diferenciado, no campo do design. Destaca-se principalmente que na fase de diagnóstico, com uso do modelo CDS e Canvas, vários aspectos não percebidos anteriormente pela gestão foram evidenciados como fatores passíveis de intervenção. A formulação de ações de intervenção também serviu para demonstrar que todo o discurso acerca de design é primordial para um pensamento estratégico da organização, pois quando as ações são planejadas e convergem para um fator comum, todos os envolvidos são beneficiados.

Com a formulação das estratégias evidenciadas neste estudo, espera-se ampliar a eficiência destes resultados com a operacionalização das estratégias. Entendendo-se a importância e os resultados alcançados no estudo, ainda, se visualiza um aprofundamento em questões que posteriormente podem ser analisadas, envolvendo a evolução na representação da identidade corporativa e melhoria da comunicação.

De forma específica, quanto aos objetivos definidos neste estudo, em sua totalidade foram alcançados, sejam de cunho teórico (revisão bibliográfica) e os de cunho prático (estudos de caso) possibilitando uma aproximação à realidade de um 
setor, bem como o desenvolvimento integrado de estratégias de design. Neste sentido, almeja-se continuar o desenvolvimento de projetos contemplando a área de Gestão de Design.

\section{Agradecimentos}

Coordenação de Aperfeiçoamento de Pessoal de Nível Superior (CAPES).

\section{Referências}

AQUINO, M. W. Evolução do modelo de negócio no processo empreendedor de start-ups: um estudo exploratório. 122 p. Dissertação (Mestrado em Administração de Empresa). Universidade Presbiteriana Mackenzie, São Paulo, 2015

BALLARD, G.; KOSKELA, L. On the agenda of Design Management research. In: Proceedings IGLC '98. Disponível em: $<$ https://www.researchgate.net/profile/Glenn

Ballard/publication/244446215 Towards Lean Design Management/links/00b495 24f6f6aebf4d000000.pdf>. Acesso em: 26 abr. 2020.

BARRERA, Y. N. I. G. La Cultura del Diseño, estrategia para la generación de valor e innovación en la PyMe del Área Metropolitana del Centro Occidente. Cuad. Cent. Estud. Diseño Comum., Colombia, n. 34, dez. 2010.

CANCLINI, N. G. Culturas híbridas. 4.ed. São Paulo: USP, 2008.

DEN OTTER, A.; EMMITT, S. Design team communication and design task complexity - The preference for dialogues. In: Architectural Engineering and Design Management, v. 4, 2008. p. 121-129.

DU GAY, P. et al. Doing Cultural Studies: The Story of the Sony Walkman. Londres: Sage, 1997.

FASCIONI, Lígia. DNA Empresarial: Identidade corporativa como referência estratégica. São Paulo: Integrare Editora, 2010.

GIL, A. C. Métodos e técnicas de pesquisa social. 6. ed. São Paulo: Atlas, 2010.

KESTLE, L. The development and validation of a conceptual design management model for international collaborative remote site projects. In: Unpublished PhD thesis. University of Canterbury, Christchurch, New Zealand, 2009.

KESTLE, L.; LONDON, K. Towards the development of a conceptual design management model for remote sites. In: Proceedings of the 10th Annual Conference on Lean Construction IiGLC-10, Gramado, Brazil, UFRGS, Brazil, 68 August, 2002, p. 309-322. 
MARTINS, R. F. F.; MERINO, E. A. D. A. Gestão de design como estratégia organizacional. 2. ed. Londrina: Eduel, 2011.

MORAES, D. Metaprojeto: o Design do Design. São Paulo: Edgard Blucher, 2010.

MOZOTA, B. Gestão do Design: usando o design para construir valor de marca e inovação corporativa. Porto Alegre: Bookman, 2011.

NGD/UFSC. Núcleo de Gestão de Design - UFSC. disponível em: http://www.ngd.ufsc.brl. Acesso em 23 mar. 2020.

NIEMEYER, L. Elementos de semiótica aplicados ao design. Rio de Janeiro: $2 A B, 2007$.

OSTERWALDER, A. The Business Model Ontology: a proposition in a design science approach. 2004. 169 f. Tese (Doutorado) - Curso de Ecole Des Hautes Etudes Commerciales, Universite de Lausanne, Lausanne, Suiça, 2004.

STICKDORN, M.; SCHNEIDER, J. (Org.). Isto é design thinking de serviços. Porto Alegre: Bookman, 2014.

VILLAS-BOAS, A. Identidade e cultura. Rio de Janeiro: 2AB, 2002. 